\title{
Rancang Bangun Monitoring Gas Belerang Oksida Berbasis Internet of Things Studi Kasus Gunung Ijen
}

\section{The Design and Construction of Sulfur Oxide Gas Monitoring based on Internet of Things for Ijen Mount Case Study}

\author{
Muhammad Arifin Ardi ${ }^{1, *}$, Fellian Helmi Pristianto ${ }^{2}$, Muhammad Nurkahfi $^{3}$, Ratna Mustika Yasi ${ }^{4}$ \\ 1,2,3,4 Program Studi Teknik Elektro, Fakultas Teknik, Universitas PGRI Banyuwangi \\ Banyuwangi, Indonesia \\ 1,*Penulis korespondensi: ardyengineer@gmail.com \\ ${ }^{2}$ hfellian@gmail.com, ${ }^{3}$ kahfi040898@gmail.com, ${ }^{4}$ nanacan12@gmail.com
}

Received on 13-06-2019, accepted on 01-08-2019, published 06-08-2019

\begin{abstract}
Abstrak
Gunung ljen merupakan salah satu Gunung berapi yang memiliki lapangan solfatara dan selalu melepaskan gas vulkanik dengan konsentrasi belerang yang tinggi dan dapat mengiritasi saluran pernafasan. Modul sensor gas MQ136 merupakan sensor yang dapat mendeteksi keberadaan gas belerang dengan jarak pembacaan antara 0 sampai dengan 100 ppm (parts per million). Modul sensor gas MQ136 difungsikan sebagai komponen aktif yang digunakan untuk membaca fenomena fisis konsentrasi gas belerang dan IC (Integrated Circuit) ATmega2560 digunakan sebagai penerima data ADC (Analog to Digital Converter) dari modul sensor gas MQ136. Data ADC yang diterima oleh IC ATmega2560 kemudian kirimkan ke modul ESP8266 Node MCU melalui serial UART (Universal Asynchronous Receiver Transmitter) dan kemudian data tersebut dikirimkan ke server menggunakan akses internet melalui modul ESP8266 Node MCU. Sehingga pengguna dapat mengetahui konsentrasi gas belerang di Gunung ljen melalui web secara realtime kapanpun dan dimanapun pengguna berada. Hasil uji coba menggunakan simulasi miniatur Gunung ljen dan bantun asap gas yang dihasilkan dari asap serbuk flare menunjukkan bahwa prototype dapat berfungsi memonitoring gas belerang dengan kadar konsentrasi tertentu yang ditunjukkan pada konsentrasi 0 ppm sampai 15 ppm.
\end{abstract}

Keywords: ATmega2560, ESP8266 Node MCU, Internet of Things, Sensor gas MQ136.

\section{Abstract}

Mount ljen is one of the volcanoes with a solfatara field and always releases volcanic gas with a high sulfur concentration and can irritate the respiratory tract. The MQ136 gas sensor module is a sensor that can detect the presence of sulfur gas with a reading range from 0 to $100 \mathrm{ppm}$ (parts per million). The MQ136 gas sensor module functions as an active component used to read the physical phenomenon of sulfur gas concentration, and IC 


\begin{abstract}
(Integrated Circuit) ATmega2560 is used as the ADC (Analog to Digital Converter) data receiver from the gas sensor module MQ136. The ADC data received by the ATmega2560 IC is then sent to the ESP8266 Node MCU module via serial UART (Universal Asynchronous Receiver Transmitter), and then the data is sent to the server using internet access via the ESP8266 Node MCU module. So that users can find out the concentration of sulfur gas in Mount ljen via the web in real-time whenever and wherever the user is. The test results using a miniature simulation of Mount ljen and gas fumes produced from powder flare smoke show that the prototype can monitor sulfur gas with a particular concentration level indicated at a concentration of $0 \mathrm{ppm}$ to $15 \mathrm{ppm}$.
\end{abstract}

Keywords: ATmega2560, ESP8266 Node MCU, Internet of Things, MQ136 gas sensor.

\title{
I.PENDAHULUAN
}

Gunung Ijen adalah gunung berapi yang ramai dikunjungi oleh wisatawan lokal maupun mancanegara ${ }^{[1][2]}$, gunung yang mempunyai danau kawah yang luas dan mempunyai derajat keasaman yang tinggi $(\mathrm{pH}<0.2)^{[3]}$. Lapangan solfatara gunung Ijen selalu melepaskan gas belerang dengan konsentrasi tinggi dengan bau sangat menyengat yang kadang menyebabkan iritasi pada saluran pernafasan ${ }^{[4]}$. Gas belerang oksida $\left(\mathrm{SO}^{\mathrm{x}}\right)$ adalah gas yang terdiri dari gas belerang dioksida $\left(\mathrm{SO}^{2}\right)$ dan gas belerang trioksida $\left(\mathrm{SO}^{3}\right)$, kedua gas tersebut memiliki sifat yang berbeda, gas $\mathrm{SO}^{2}$ memiliki bau sangat menyengat dan tidak mudah terbakar, sedangkan gas $\mathrm{SO}^{3}$ bersifat sangat reaktif dan mudah bereaksi terhadap uap air $\left(\mathrm{H}_{2} \mathrm{SO}_{4}\right)^{[5]}$. Gas belerang dapat memicu gangguan pernafasan dan beberapa penyakit kardiovaskular, dan pada tingkat konsentrasi tertentu gas belerang dapat mengkorosi suatu lingkungan yang didominasi oleh proses sulfidasi $\mathrm{SO}^{2[6]}$. Pentingnya menjaga kesehatan dari paparan gas belerang menuntut adanya suatu alat yang dapat digunakan untuk memantau konsentrasi gas belerang di lapangan solfatara gunung Ijen, sensor gas MQ136 merupakan suatu sensor yang dapat membaca konsentrasi gas belerang dengan mksimum pembacaan 100 ppm, data yang diterima oleh sensor akan dikirimkan ke server menggunakan akses internet untuk ditampilkan ke pengguna melalui web. Sehingga diharapkan dari alat tersebut dapat membantu pengunjung wisata gunung Ijen untuk memantau konsentrasi gas belerang secara realtime agar pengunjung dapat mengantisipasi diri dari paparan gas polutan gunung Ijen.

\section{II.KAJIAN PUSTAKA}

Ada dua macam gas SOx yaitu gas SO2 dan gas SO3. Pembakaran menghasilkan gas SO2 lebih banyak dibandingkan gas $\mathrm{SO} 3$, namun dengan udara gas $\mathrm{SO} 2$ lebih cepat membentuk gas $\mathrm{SO} 3$ sehingga gas ini menjadi lebih banyak diudara. Pada konsentrasi $0,4 \mathrm{ppm}$ gas SOx menjadi sangat berbahaya bagi manusia, akibat yang ditumbulkan adalah gangguan pada sistem pernafasan, karena gas SOx mudah menjadi asam yang menyerang selaput lendir pada hidung. Pada konsentrasi 1 smpai dengan 2 ppm bagi orang yang sensitif serangan gas SOx menyebabkan iritasi pada tubuh yang terkena radiasi langsung. Dalam paparan yang lebih lama gas SOx dapat menyebabkan peradangan hebat pada selaput lendir yang diikuti oleh kelumpuhan sistem pernafasan, kerusakan dinding ephitelium dan pada akhirnya diikuti oleh kematian ${ }^{[7]}$.

Material sensitif dari sensor jenis MQ adalah berupa Inkoporasi Oksida Timah (SnO2), yang memiliki tingkat konduktifitas yang rendah pada udara bersih. Saat sensor MQ terpapar oleh gas sulfur yang terdeteksi maka nilai konduktifitas sensor akan semakin meningkat dan sebanding dengan konsentrasi gas yang berada diudara ${ }^{[8]}$. Berdasarkan Technical Data MQ-136 Gas Sensors ${ }^{[13]}$, mengatakan bahwa sensor Gas MQ136 memiliki konduktifitas rendah pada udara bersih dan memiliki sensitivitas tinggi terhadap $\mathrm{SO} 2, \mathrm{MQ136}$ juga dapat digunakan untuk mendeteksi gas lain yang mengandung sulfur.

IoT (Internet of Things) merupakan suatu sistem yang dilengkapi dengan sensor yang sesuai dengan fungsinya yang terhubung melalui jaringan internet. Sistem IoT berfungsi untuk mengumpulkan data yang dihasilkan oleh masing-masing sistem yang terhubung ke internet untuk diolah dan dianalisis menjadi informasi yang berguna, sehingga dapat digunakan untuk memantau dan mengontrol suatu benda ${ }^{[9]}$.

ESP8266 Node MCU merupakan sebuah platform IoT dan pengembangan kit yang digunakan untuk membantu membuat prototipe produk IoT, ESP8266 Node MCU mengintegrasikan GPIO (General Purpose Input Output), PWM (Pulse Width Modulation), IIC (Inter Integrated Circuit), dan ADC (Analog to Digital 
Converter) dan semua dalam satu board. ESP8266 Node MCU menggunakan serial WiFi SoC (Single on Chip) dengan onboard USB to TTL dengan menggunakan wireless IEE $802.11 \mathrm{~b} / \mathrm{g} / \mathrm{n}^{[10]}$.

ATmega2560 merupakan sebuah IC (Integrated Curcuit) mikrokontroler yang mempunyai 54 bit GPIO, dimana 15 bit digunakan sebagai bit PWM, 16 bit sebagai ADC dan 4 bit sebagai UART. ATmega2560 memakai osilator sebesar $16 \mathrm{MHz}$ (Mega Hertz) dan ICSP (In Circuit Serial Programming) sebagai downlodernya ${ }^{[11]}$.

\section{III.Metode Penelitian}

\section{A. Blok Diagram Sistem}

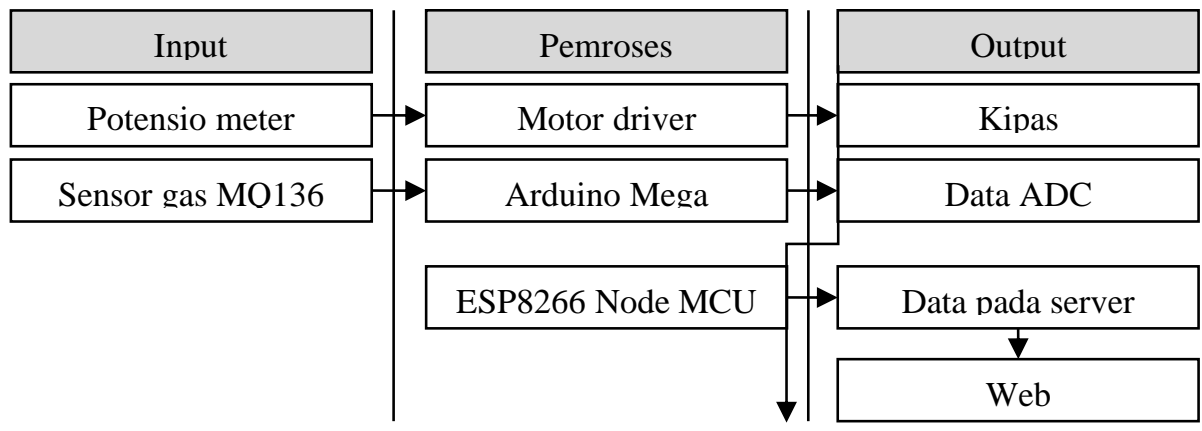

Gambar 1. Blok Diagram Sistem

Berdasarkan blok diagram di atas dapat dijelaskan bahwa sistem terdiri dari tiga subsistem, yaitu (1) Input terdiri dari dua komponen utama, yaitu potensio meter dan sensor gas MQ136. Potensio meter berfungsi untuk mengatur dan menentukan kecepatan putaran kipas, dan sensor gas MQ136 berfungsi sebagai pendeteksi gas belerang. (2) Pemroses terdiri dari motor driver, mikrokontroler Arduino Mega dan ESP8266 Node MCU yang berfungsi sebagai pusat pengolahan data dan interkoneksi antara sistem yang satu dengan sistem yang lain. (3) Output terdiri dari kipas sebagai sumber angin, data ADC adalah hasil nilai pembacaan sensor gas MQ136 dan data server adalah data yang akan diakses oleh pengguna melalui web.

\section{B. Skema Rangkaian Sistem}

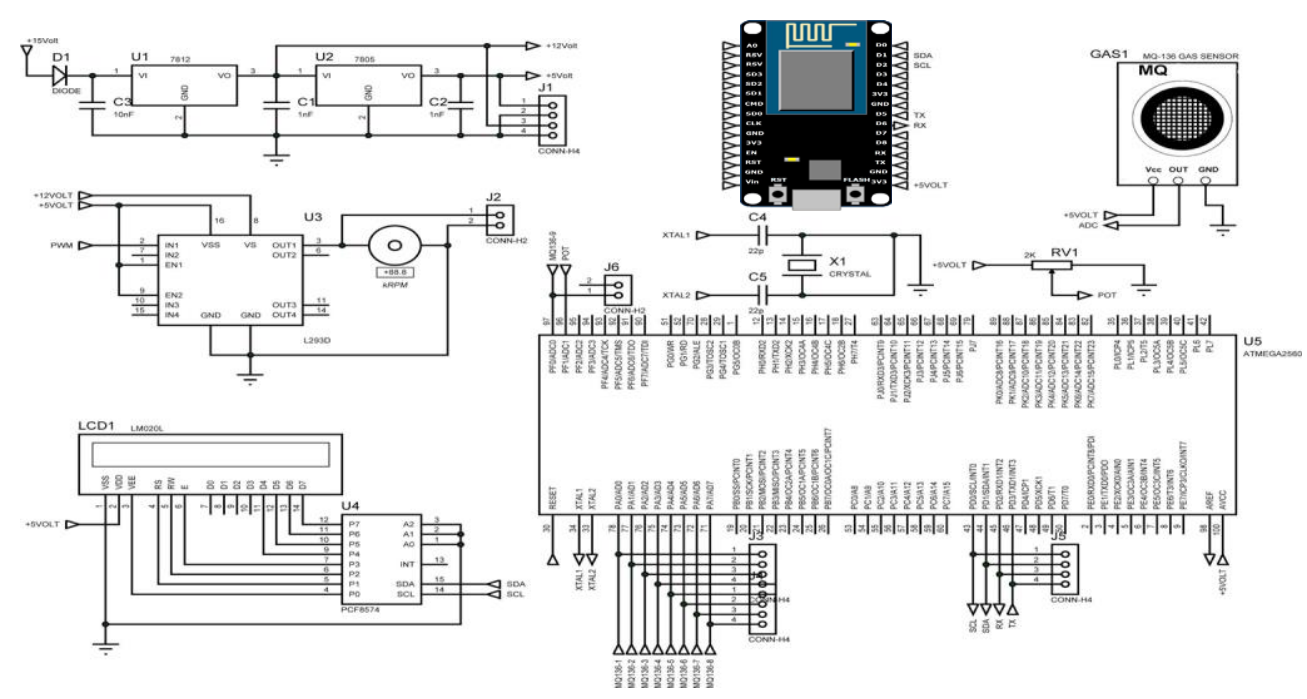

Gambar 2. Skema Rangkaian Sistem 
Gambar diatas adalah skema rangkaian sistem yang digambar menggunakan Software Proteus Professional Suite 8.

\section{Desain Miniatur Gunung Ijen}

Pembuatan miniatur gunung Ijen digunakan untuk mempermudah proses uji coba dan analisis alat, untuk desainnya dapat dilihat pada gambar di bawah.

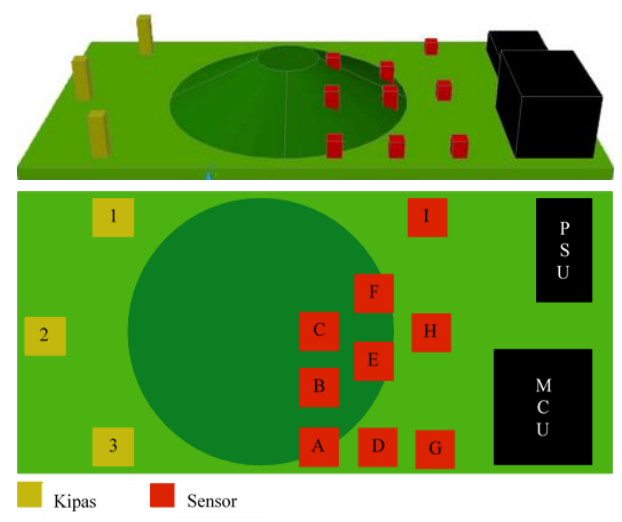

Gambar 3. Desain 3 Dimensi Minitur Gunung Ijen

Setelah pembutan miniatur gunung ijen selesai maka tahap selanjutnya adalah membuat tabung asap yang akan digunakan untuk menyimpan asap sementara sebagai sumber asap untuk miniatur gunung ijen, untuk desainnya dapat dilihat pada gambar di bawah.



Gambar 5. Desain 3 Dimensi Tabung Asap

\section{Pembuatan Web}

Pembuatan web dibuat menggunakan bahasa pemrograman HTML5 (Hypertext Markup Language Version 5), CSS3 (Cascading Style Sheets Version 3), dan JavaScript. Program ditulis pada software editor program Notepad++ versi 7.6. dan dijalankan pada software Mozilla Firefox. Pada pembuatan tampilan grafik pada web, penulis menggunakan perpustakaan sumber terbuka dari highchart.com dan perpustakaan JavaScript JQuery.

\section{E. Pembuatan Server}

Pada tahap pembuatan server yang akan digunakan untuk menyimpan data sementara ataupun menyimpan data secara permanen, disini penulis menggunakana penyedia jasa layanan server dari Firebase dalam versi trial, sebuah anak dari perusahaan terkemuka Google. Penulis memilih Firebase karena pada 
versi trial-nya Firebase menyediakan penyimpanan sebesar 1GB (Giga Byte) dan traffict download sebesar 10GB.

\section{F. Kalibrasi Sensor Gas MQ136}

Proses kalibrasi sensor mengacu pada datasheet sensor yang telah ditetapkan oleh pembuatnya, untuk karakteristik sensor MQ136 dapat dilihat pada gambar berikut.

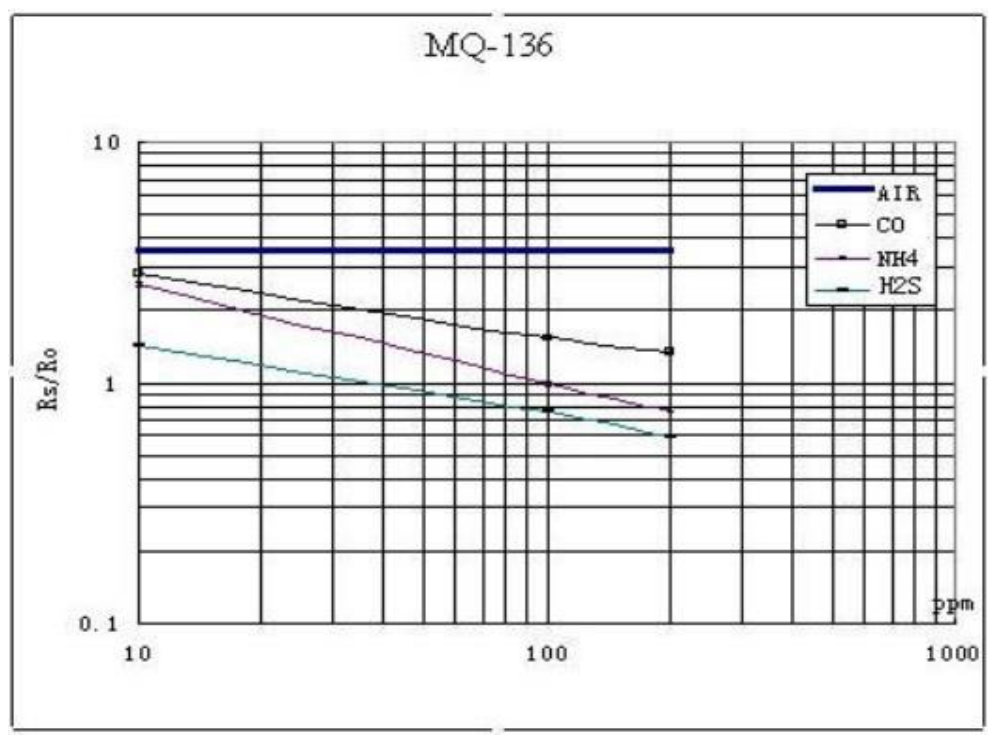

Gambar 6. Karakteristik Sensor Gas MQ136

Berdasarkan pada grafik di atas dapat diambil kesimpulan bahwa nilai rasio resistansi konduktivitas sensor adalah berbanding terbalik terhadap konsentrasi gas $\mathrm{SO}$, sehingga dapat ditulis persamaan sebagai berikut[12][13].

$$
\begin{aligned}
& \frac{R s}{R o}=\frac{1}{K G s} \\
& K G s=\frac{R o}{R s} \\
& \text { Persamaan Rs }=\left(\frac{V c}{V R L}-1\right) \times R L
\end{aligned}
$$

Keterangan:

$$
\begin{array}{ll}
\mathrm{Vc} & =\text { Tegangan uji sensor }(\text { Volt }) \\
\mathrm{VRL} & =\text { Tegangan keluaran }(\text { Volt }) \\
\mathrm{Rs} & =\text { Resistansi sensor }(\mathrm{Ohm}) \\
\mathrm{Ro} & =\text { Resistansi sensor pada saat } 50(\mathrm{Ppm}) \\
\mathrm{KGs} & =\text { Konsentrasi gas }(\mathrm{ppm}) \\
\mathrm{RL} & =\text { Beban resistansi }(\mathrm{Z})
\end{array}
$$

\section{G. Skenario Pengujian Alat}

Pengujian alat dilakukan menggunakan simulasi gunung ijen, pertama setelah prototipe dinyalakan dan telah tersambung ke jaringan hostspot/tethering seluler maka dilanjutkan dengan pembakaran serbuk flare didalam tabung asap yang telah dibuat, setelah pembakaran serbuk flare selesai kemudian asap dihisap 
menggunakan pompa air aqurium dan asap disalurkan ketitik tengah gunung pada miniatur menggunakan selang, setelah asap keluar dari miniatur gunung tahap selanjutnya adalah asap tiup menggunakan kipas agar pergerakan kipas dapat terarah. Setelah pergerakan asap terarah dengan baik, maka tahap selanjutnya yag dilakukan adalah melakukan analisis terhadap prototipe.

\section{IV.HASIL DAN PEMBAHASAN}

Berdasarkan hasil pengujian sistem yang dilakukan dengan cara menempatkan sensor gas MQ136 pada titik yang telah ditentukan pada miniatur gunung Ijen. Selanjutnya membuat asap didalam tabung asap yang telah dibuat, asap diperoleh dari pembakaran serbuk flare, ada beberapa bahan yang bisa digunakan untuk membut asap tiruan, diantaranya adalah serbuk petasan, kertas, kayu, kulit kelapa, dan lain sebagainya, serbuk flare dipilih karena memiliki ketebalan asap yang tebal dan bau yang menyengat, kemudian asap di dalam tabung dihisap menggunakan pompa air aquarium dengan kuat hembusan pompa sebesar 11.2 Kmph (Kilometer per hour) dengan kecepatan konstan, kuat hembusan diatur pada $11.2 \mathrm{Kmph}$ karena pada kondisi ini asap dapat terhisap dari dalam tabung asap dengan baik. Kipas digunakan untuk mengatur pergerakan arah asap dan dinyalakan dengan kuat sehingga menghasilkan hembusan angin yang merata keseluruh area simulasi, kecepatan yang dihasilkan sebesar $6.6 \mathrm{Kmph}$ dengan kecepatan yang konstan, kecepatan putaran kipas diatur secara konstan karena pada kondisi ini pergerakan asap dapat terarah dengan baik dan tidak kehilangan ketebalannya.

Hasil uji coba menunjukkan bahwa prototipe dapat berkerja dengan baik, sensor gas MQ136 dapat membaca konsentrasi gas antara 0 ppm sampai dengan 15 ppm selama pengujian dari tiruan asap belerang yang dipakai, hal ini menunjukkan bahwa sensor gas dapat berkerja dengan baik dan sesuai dengan datasheet penyedia sensor, yang mengatakan kepekaan sensor terhadap gas belerang antara 0 ppm sampai dengan 100 ppm. Berdasarkan hasil pengujian alat diperoleh nilai konsentrasi gas sebesar 3.3 ppm dengan merujuk pada persamaan kalibrasi sensor gas MQ136 ${ }^{[12][13]}$. Modul ESP8266 Node MCU sebagai sumber jaringan internet didapat dari hostspot/tethering seluler dengan kualitas signal 4G LTE, pada saat proses pengujian, board ESP8266 Node MCU sudah berkerja dengan baik dan dapat menyimpan data pada server dengan kecepatan pengiriman data sebesar 2 detik dengan minimum bandwidth 200 Kbps (Kilo bit per seconds).

Proses pengiriman data dari prototipe hingga bisa dilihat pada web menggunakan dua sintaks pemrograman, sintaks tersebut telah disediakan oleh Firebase. Pertama adalah dengan metode push, metode ini dilakukan untuk menambahkan setiap data baru yang masuk ke server Firebase sehingga pada web dapat dilihat data statistik keseluruhan pada saat proses pengujian. Kedua adalah dengan menggunakan metode set, metode ini digunakan untuk melakukan penimpaan pada setiap data baru yang diterima server Firebase sehingga pada proses ini data dapat diperbarui secara otomatis tanpa harus melakukan reload pada web. Selama proses pengujian prototipe hasil data realtime dan statistik dapat dilihat pada web, dan berikut adalah tampilan web yang dapat diakses oleh pengguna.



Gambar 7. Halaman Utama Web Monitoring Gas Belerang 


\section{V.KESIMPULAN}

Berdasarkan pembuatan dan pengujian yang telah dilakukan, sensor gas MQ136 dapat membaca konsentrasi gas belerang pada rentang nilai antara 0 ppm sampai dengan 35 ppm dengan pemberian gas belerang pekat. Sistem pengiriman data menggunakan ESP8266 Node MCU ke server didapatkan akurasi data sebesar $100 \%$ tanpa kehilangan data dengan kecepatan transfer sebesar 2 detik pada bandwidth diatas $200 \mathrm{Kbps}$. Web dapat meminta data dari server secara realtime dan dapat menampilkan data dengan kecepatan 1 detik.

\section{ACKNOWLEDGEMENT}

Penulis berterima kasih kepada Tuhan Y.M.E, kepada kedua orang tua, kepada seluruh civitas akademi Universitas PGRI Banyuwangi pada umunya, dan khususnya para dosen dan mahasiswa program studi S1 teknik elektro yang telah mendukung penulis dalam menyelesaikan rancang bangun ini.

Dibiayai oleh: Direktorat Kemahasiswaan. Direktorat Jenderal Pembelajaran dan Kemahasiswaan. Kementrian Riset, Teknologi dan Pendidikan Tinggi. Program Kreativitas Mahasiswa (PKM) 5 Bidang Tahun 2019. Nomor 754/SPK/KM.02.01/2019 Tanggal 22 April 2019.

\section{REFERENCES}

[1] Fitroh S. K., 2017., Pengaruh Atraksi Wisata dan Motivasi Wisatawan Terhadap Keputusan Berkunjung., Jurnal Administrasi Bisnis Vol. 42 No. 2.

[2] Nurmalasari T. R., 2017., Analisis Faktor Yang Mempengaruhi Pengunjung Objek Wisata Kawah Ijen Banyuwangi., Surabaya: Universitas Negeri Surabaya.

[3] Zaenuddin A., Wahyudin D., Surmayadi M., Kusnidar E., 2012., Prakiraan Bahaya Letusan Gunung Api Ijen Jawa Timur., Jurnal Lingkungan dan Bencana Geologi Vol. 3 No. 1.

[4] Kementrian Energi dan Sumber Daya Mineral., 2014., G. Ijen., Retrieved from Kementrian Energi dan Sumber Daya Mineral Junaedi., 2017., Pengaruh Paparan Asap Belerang Terhadap Faal Paru Pekerja Tambang Belerang Di Kawah Ijen Banyuwangi., Malang: Universitas Muhammadiyah Malang.

[5] Rakhman A. N., 2016., Peranan Sulfur Dioksida Pada Pembentukan Korosi Logam dan Implikasinya Bagi Kesehatan Manusia di Gunung Lumpur Desa Kuwu Kecamatan Kradenan Kabupaten Grobogan Provinsi Jawa Tengah., Jurnal Teknologi Technoscientia Vol. 8 No. 2.

[6] Sugiarti., 2009., Gas Pencemar Udara dan Pengaruhnya Bagi Kesehatan Manusia., Jurnal Chemica Vol. 10 No. 1.

[7] Simamora J., 2017., Rancang Bangun Sistem Pendeteksi Kesegaran Daging Berdasarkan Bau dan Warna., Surabaya: Institut Teknologi Sepuluh Nopember.

[8] Cahyono G., 2015., Internet of Things. Jurnal Forum Teknologi Vol. 6 No. 3.

[9] Arranda D. F., 2017., NodeMCU Pada Home Automation Control., Jurnal Informatika dan Komputer Vol. 1 No. 1.

[10] Alimuddin., 2018., Sistem Parkir Cerdas Sederhana Berbasis Arduino Mega 2560 Rev 3., Jurnal Elektro Luceat Vol. 4 No. 1.

[11] Rahajoeningroem T., Fergo T., 2017., Rancang Bangun Warning System dan Monitoring Gas Sulfur Dioksida (SO2) Gunung

[12] Tangkuban Perahu Via SMS Gateway Berbasis Mikrokontroler Menggunakan Sensor MQ-136., Telekontran Vol. 5 No. 1.

[13] Technical Data MQ-136 Gas Sensor., www.sensorica.ru/pdf/MQ-136.pdf., Diakses pada 17 Mei 2019. 